\title{
Perbandingan Sensitivitas Kontras antara Lensa Tanam Asferik dan Sferik Post Fakoemulsifikasi
}

\section{Comparison of Aspheric and Spherical Intra Ocular Lenses Contrast Sensitivity Post Phacoemulsification}

\author{
Helen Nguda, T Budi Sulistya, Seskoati Prayitnaningsih \\ Laboratorium IImu Kesehatan Mata Rumah Sakit Umum Dr. Saiful Anwar Malang
}

\begin{abstract}
ABSTRAK
Lensa tanam asferik dapat mengurangi aberasi sferik yang terjadi pasca operasi katarak, dan meningkatkan sensitivitas kontras dibandingkan lensa tanam sferik. Penelitian ini membandingkan sensitivitas kontras antara pasien yang diberi lensa tanam asferik dan sferik dengan menggunakan lembar kartu Pelli-Robson yang telah dilakukan dengan metode observasi cross sectional. Pemeriksaan dilakukan pada 32 mata yang diambil secara konsekutif dari 23 pasien minimal 1 bulan setelah dilakukan fakoemulsifikasi dan penanaman lensa tanam (asferik dan sferik). Sensitivitas kontras diperiksa pada jarak $1 \mathrm{~m}$ di depan lembar kartu dengan tajam penglihatan terbaik pasien setelah koreksi (log MAR) dan keratometri kurang dari 1,5Dioptri (D). Berdasarkan data demografi dan data operasi tidak didapatkan perbedaan yang signifikan, sensitivitas kontras lebih tinggi pada lensa tanam asferik dibandingkan sferik dengan independent $t$ test. Perbedaan yang signifikan ini dapat menjadi pertimbangan untuk pemilihan lensa tanam yang sesuai dengan kebutuhan agar pasien mendapatkan fungsi penglihatan terbaiknya.
\end{abstract}

Kata Kunci: Lensa tanam asferik, lensa tanam sferik, Pelli-Robsoncontrast sensitivity

\section{ABSTRACT}

Aspheric intra ocular lenses (IOL) improve the contrast sensitivity compared to spheric IOL by decreasing spherical aberration post phacoemulsification. This study comparing of contrast sensitivity (cs) between aspheric and spherical IOL from patients using Pelli-Robson cs chart with cross sectional observational design. Thirty two eyes was evaluated consecutively from 23 cataract patients who underwent phacoemulsification and IOL implantation (aspheric and spherical) at least 1 month. Contrast sensitivity was evaluated at 1 meter distance with corrected visual acuity (bcva) in log MAR less than 1,50D. There was no statistical difference revealed on age $(p=0,704)$ and surgery data like phacotime (pt) $(p=0,455)$, effective phacotime (ept) $(p=0,222)$, fluid (fl) $(p=0,255)$, bcva $(p=0,073)$ and $k r(p=0,266)$. The contrast sensitivity was significantly higher for aspheric IOL compare to spherical IOL. The significant differences between aspheric and spherical IOL could be considered in deciding IOL implantation for cataract phacoemulsification to achieve the best visual quality.

Keywords: Aspheric IOL, spherical IOL, Pelli-Robson contrast sensitivity

Jurnal Kedokteran Brawijaya, Vol. 28, No. 1, Februari 2014; Korespondensi: Helen Nguda. Laboratorium Ilmu Kesehatan Mata Rumah Sakit Umum Dr. Saiful Anwar Malang, Jl. Jaksa Agung Suprapto No. 2 Malang Tel. (0341)341945 Email: umihanawafa79@gmail.com 


\section{PENDAHULUAN}

Keberhasilan operasi katarak dengan pemasangan intra ocular lense (IOL) tidak hanya diukur dengan perbaikan visual acuity (va), tetapi juga diharapkan dapat memberikan kualitas terbaik untuk pasien. Setelah operasi keluhan yang kadang disampaikan pasien adalah adanya bayangan tambahan pada penglihatannya seperti host image, glare atau halo yang terjadi akibat adanya peningkatan aberasi sferik $(1,2)$.

Pergeseran aberasi sferik pada lensa baik itu negatif atau positif, bergabung dengan aberasi sferik dari kornea yang positif akan berdampak pada kualitas optikokular. Kornea memiliki nilai aberasi sferik positif yang lebih sedikit dan bersifat konstan dibandingkan lensa. Lensa alami manusia lebih bersifat kinetik, pada usia muda bernilai negatif, bernilai nol pada usia pertengahan dan dengan semakin bertambahnya usia dimana lensa menjadi lebih bundar akibat terbentuknya sklerosis pada nucleus lensa menyebabkan aberasi sferik yang semakin bergeser kearah positif. Bentuk IOL sferik yang dibuat semirip mungkin dengan lensa natural yang berbentuk equibiconvex atau convexplano sehingga menimbulkan hal yang sama yaitu peningkatan aberasi sferik setelah operasi katarak (3-6).

Saat ini telah dikembangkan lensa tanam asferik dengan nilai aberasi sferik negatif yang dapat menurunkan nilai aberasi sferik dan meningkatkan sensitivitas kontras sehingga diharapkan dapat meningkatkan kualitas penglihatan pasien setelah operasi katarak. Beberapa studi sebelumnya dilakukan untuk membandingkan antara lensa tanam asferik dengan sferik, Ohtani et al menyatakan adanya penurunan aberasi sferik serta peningkatan sensitivitas kontras yang signifikan pada keadaan scotopic antara IOL silicon aspherik (Tecnis Z9000; AMO Inc) dibandingkan IOL silicon spheris (CeeOn 911A; AMO Inc) selama satu tahun follow up, namun tidak didapatkan perbedaan sensitivitas kontras pada kondisi photopic dan mesopic (3). Sandoval et al menyatakan bahwa perbandingan antara IOL asferik (Acrysof IQ) dengan IOL sferik (Acrys of Single-piece) tidak didapatkan perbedaan sensitivitas kontras yang signifikan pada kondisi photopic setelah operasi 1 dan 3 bulan, namun didapatkan penurunan aberasi sferik yang signifikan (1). Berbeda dengan Trueb et al yang menyatakan adanya perbedaan sensitivitas kontras yang signifikan antara IOL asferik (Acrysof IQ) dibandingkan IOL sferik (Acrysof SN60AT) pada kondisi potopic dan mesopic $(7,8)$. Santhiago et al membandingkan IOL asferik (Akreos Advanced Optic; Bausch \& Lomb, Inc) dengan IOL sferik (Akreos Fit; Bausch \& Lomb, Inc) dan mengidentifikasi adanya perbedaan sensitivitas kontras yang signifikan dengan kondisi mesopic dan photopic (9). Tujuan dari penelitian ini untuk menunjukkan adanya perbedaan sensitivitas kontras antara pasien yang ditanam IOL asferik dengan IOL sferik pada pasien post fakoemulsifikasi yang diperiksa dengan Pelli-Robson chart letters.

\section{METODE}

Penelitian ini merupakan penelitian observasional analitik dengan pendekatan cross sectional. Pada saat pasien melakukan pemeriksaan ulang satu bulan atau lebih setelah operasi katarak dengan fakoemulsifikasi, dilakukan pemeriksaan sensitivitas kontras dengan PelliRobson cs chart. Penelitian dilakukan di Klinik Mata
Malang, pada bulan Maret sampai dengan Juni 2013. Sampel diambil secara konsekutif, melibatkan 32 mata dari 23 pasien katarak yang telah dilakukan katarak ekstraksi minimal satu bulan dengan teknik fakoemulsifikasi dan penanaman lensa tanam yang dilakukan oleh satu orang operator ahli.

Data demografi yang diambil dari rekam medis yaitu usia, jenis kelamin, dan tajam penglihatan dengan koreksi terbaik (bcva; best correction visual acuity). Kriteria inklusi meliputi katarak primer, tekanan intra okuli normal, tidak ada kelainan mata seperti glaukoma, retinopati atau kelainan segmen anterior dan posterior lainnya yang dapat mempengaruhi fungsi penglihatan dan/atau sensitivitas kontras, tidak ada riwayat operasi mata sebelumnya selain fakoemulsifikasi pada satu atau kedua mata, astigmat keratometrik post operasi 1,5D, tidak ada komplikasi saat operasi (perdarahan COA, kerusakan iris, ruptur kapsul posterior, vitreous loss, ruptur zonular).

Fakoemulsifikasi adalah salah satu teknik katarak ekstraksi dengan prosedur dinamik untuk menghancurkan lensa (phaco) hingga teremulsifikasi menjadi lebih lunak atau serpihan kecil (emulsification) yang kemudian di aspirasi dengan mesin'Infinity' vision system (Alcon Laboratories Inc) dan penanaman lensa tanam asferik dengan Acrysof IQ SN60WF (Alcon Inc, USA) dan sferik dengan Acrysof SA60AT (Alcon Inc, USA). Semua pasien yang dioperasi menggunakan insisi clear cornea $2,2 \mathrm{~mm}$, viskoelastik viscoat dan cairan BSS. Beberapa data operasi dicatat seperti: fluid (fl) yaitu jumlah cairan yang digunakan selama operasi. Phako time (pt) adalah akumulasi waktu (menit) yang tercatat pada mesin fako dimulai sejak kaki menginjak pedal di posisi 3 , nilainya menjadi 0 pada saat injakan penuh atau pada saat power fako $100 \%$. Effective phaco time (ept) adalah total waktu fako (detik) yang digunakan pada saat power fako $100 \%$, dengan waktu kurang dari pt. Rumus ept adalah pt dikalikan power. Keratometri $(\mathrm{kr})$ post operasi diperiksa dengan autorefraktokeratometri (Canon Inc, Japan), tekanan intra okuli diperiksa dengan computerized tonometer-80 (Topcon corporation, Japan). Segmen posterior diperiksa dengan ophthalmoskop direk (Neitz instrument, Japan). Sensitivitas kontras diperiksa dengan Pelli-Robson cs chart (Haag Streit, United Kingdom) dengan kondisi cahaya 28 lux.

Sensitivitas kontras adalah pemeriksaan yang dilakukan untuk mengetahui kemampuan mata membedakan kontras antara objek dengan latarnya (antara terang dan gelap) yang diperiksa dengan Pelli-Robson cs chart (Haag Streit, United Kingdom), dilakukan pada minimal satu bulan pertama setelah operasi pada kondisi pencahayaan 28 lux. Pemeriksaan dilakukan pada pupil natural pada jarak 1 meter dari chart dengan perbedaan level tiap triplet pada kontras sebesar 0,15 log unit, dihentikan saat terjadi 2 kesalahan pada 1 triplet, skor dinilai berdasarkan huruf. Sebelum pasien diperiksa kontras terlebih dahulu dilakukan pemeriksaan keratometri dan bcva, dan pemeriksaan kontras dilakukan pada mata pasien dengan $\mathrm{kr}$ 1,50D dan telah mendapatkan tajam penglihatan terbaiknya dengan koreksi refraksi menggunakan logaritma (log MAR).

Jumlah sampel dihitung dengan rumus untuk rerata dua populasi dengan data numerik yang diambil dari data penelitian pendahuluan. Sampel dihitung untuk tingkat signifikansi 0,05 dengan kepercayaan 95\%. Uji normalitas dan homogenitas untuk sensitivitas kontras terhadap IOL 
asferik dan IOL sferik menggunakan uji Kolmogorov Smirnov dan uji levene, sedangkan yang digunakan untuk membandingkan sensitivitas kontras antara lensa tanam asferik dan sferik adalah independent sample $t$ test. Analisa data menggunakan SPSS 15.

\section{HASIL}

Karakteristik pasien (Tabel 1) menggambarkan distribusi pasien pada setiap karakteristik yang diamati meliputi usia pasien, jenis kelamin dan jumlah mata kanan atau mata kiri. Berdasarkan usia pasien yang masuk dalam penelitian ini adalah antara 41 sampai 80 tahun dengan rata-rata $64,7(10,02)$ pada kelompok pasien yang dipasang IOL asferik dan $66,0(5,87)$ pada kelompok pasien yang dipasang IOL sferik dan didapatkan nilai yang signifikan sebesar 0,704 ( $p>0,05)$. Berdasarkan jenis kelamin pada kelompok asferik terdapat 12 pasien yang terdiri dari 6 laki-laki dan 6 perempuan, sedangkan kelompok sferik terdapat 11 pasien yang terdiri dari 4 laki-laki dan 7 perempuan, dimana dari kedua kelompok tersebut juga didapatkan nilai yang signifikan sebesar 0,608 $(p>0,05)$.

Berdasarkan perbedaan jumlah mata kanan (OD) atau mata kiri (OS) pada pasien yang mendapat IOL asferik total sebanyak 16 mata yang terdiri dari OD 9 dan OS 7 (ODS 8 mata dari 4 pasien) sedangkan pasien yang mendapat IOL sferik total sebanyak 16 mata yang terdiri dari OD 10 dan OS 6 (ODS 10 mata dari 5 pasien) menunjukkan nilai yang signifikan sebesar $0,880(p>0,05)$. Data demografik pasien menunjukkan bahwa dari usia, jenis kelamin, serta mata kanan dan kiri tidak didapatkan perbedaan signifikan $(p>0,05)$

Tabel 1. Karakteristik sampel pada kelompok asferik (WF) dan sferik (AT)

\begin{tabular}{|c|c|c|c|c|c|}
\hline $\begin{array}{l}\text { Karakteristik } \\
\text { Demografi }\end{array}$ & $\begin{array}{c}\text { Asferik } \\
\text { (WF) }\end{array}$ & $\begin{array}{c}\text { (frek / } \\
\% \text { ) }\end{array}$ & $\begin{array}{c}\text { Sferik } \\
\text { (AT) }\end{array}$ & (frek / \%) & p-value \\
\hline Usia $\quad($ mean $\pm S D)$ & $6,4,67 \pm S$ & D 10,02 & $66,0 \pm S D$ & 5,87 & 0,704 \\
\hline \multicolumn{6}{|l|}{ Kategori usia: } \\
\hline $41-50$ th & 1 & $4,3 \%$ & 0 & $0 \%$ & \\
\hline $51-60$ th & 3 & $13 \%$ & 2 & $8,7 \%$ & \\
\hline $61-70$ th & 4 & $17,4 \%$ & 7 & $30,4 \%$ & \\
\hline $71-80$ th & 4 & $17,4 \%$ & 2 & $8,7 \%$ & \\
\hline \multicolumn{6}{|l|}{ Jenis kelamin (sex): } \\
\hline Laki-laki & 6 & $26,1 \%$ & 4 & $17,4 \%$ & \multirow{2}{*}{0,608} \\
\hline Perempuan & 6 & $26,1 \%$ & 7 & $30,4 \%$ & \\
\hline \multicolumn{6}{|l|}{ Mata pasien: } \\
\hline OD & 5 & $21,7 \%$ & 5 & $21,7 \%$ & \\
\hline OS & 3 & $13,0 \%$ & 1 & $4,3 \%$ & 0,880 \\
\hline ODS & 4 & $17,4 \%$ & 5 & $21,7 \%$ & \\
\hline
\end{tabular}

Data operasi pada Tabel 2, menunjukkan tidak ada perbedaan signifikan $(p=0,455)$ rata-rata pt pada kelompok asferik 1,25 $(0,89)$ dan kelompok sferik 1,47 $(0,74)$. Hasil effective phaco time (ept) pada kelompok asferik rata-rata $15,89(17,78)$ dan kelompok sferik 23,93 $(18,69)$ menunjukkan tidak ada perbedaan signifikan $(p=0,222)$. Perbedaan yang tidak signfikan $(p=0,255)$ juga didapatkan pada pengukuran $\mathrm{fl}$ rata-rata kelompok asferik $76,0(24,49)$ dan kelompok sferik $67,43(16,46)$. Berdasarkan data operasi tersebut juga menunjukkan bahwa nilai pt, ept, fl bahwa antara kelompok mata dengan IOL asferik (WF) dan kelompok IOL sferik (AT) tidak ada perbedaan yang bermakna.

Hasil pengukuran $\mathrm{kr}$ pada kelompok asferik -0,73 $(0,38)$ dan kelompok sferik -0,92 $(0,56)$ menunjukkan tidak ada perbedaan signifikan $(p=0,266)$, demikian pula dari hasil pengukuran tajam penglihatan dengan koreksi terbaik (bcva) pada kelompok asferik $0,83(0,19)$ dan kelompok sferik $0,71(0,18)$ menunjukkan tidak ada perbedaan signifikan $(p=0,073)$. Hasil pengujian data sensitivitas kontras antara kelompok IOL asferik $(1,62 \pm 0,05)$ dan kelompok IOL sferik $(1,52 \pm 0,13)$ menggunakan independent t-test didapatkan perbedaan signifikan $(p=0,011)$.

Tabel 2. Karakteristik data operasi dan post operasi

\begin{tabular}{lccc}
\hline \multicolumn{1}{c}{ Karakteristik } & $\begin{array}{c}\text { Asferik (WF) } \\
\text { (frek / \%) }\end{array}$ & $\begin{array}{c}\text { Sferik (AT) } \\
\text { (frek / \%) }\end{array}$ & p-value \\
\hline 1. Phaco time(pt) & $1,25 \pm S D ~ 0,89$ & $1,47 \pm S D ~ 0,74$ & 0,455 \\
2. Effective phacotime(ept) & $15,89 \pm S D ~ 17,78$ & $23,93 \pm S D ~ 18,69$ & 0,222 \\
3. Cairan (fl) & $76,0 \pm S D ~ 24,49$ & $67,43 \pm S D ~ 16,46$ & 0,255 \\
4. Keratometri (kr) & $-0,7263 \pm$ SD 0,38 & $-0,9194 \pm$ SD 0,56 & 0,266 \\
$\begin{array}{llll}\text { 5. Tajam penglihatan } \\
\text { koreksi terbaik (bcva) }\end{array}$ & $0,833 \pm S D ~ 0,19$ & $0,7113 \pm S D ~ 0,18$ & 0,073 \\
\hline
\end{tabular}

\section{DISKUSI}

Pada penelitian ini didapatkan perbedaan sensitivitas kontras yang signifikan antara kelompok mata yang ditanam IOL asferik (Acrysof IQ SN60WF, Alcon) dengan kelompok mata yang ditanam IOL sferik (Acrysof SA60AT, Alcon) pada kondisi pencahayaan 28 lux. Beberapa penelitian sebelumnya juga menyatakan adanya perbedaan signifikan antara kedua jenis IOL pada kondisi photopic. Santhiago et al pada penelitiannya terhadap 50 mata dari 25 pasien dengan bilateral katarak, dimana ditanam IOL asferik (Akreos AO, Bausch \& Lomb) pada satu mata dan IOL sferik (Akreos fit, Bausch \& Lomb) pada mata yang lainnya, menyatakan adanya perbedaan sensitivitas kontras yang signifikan pada kondisi photopic dan mesopic setelah 1 dan 3 bulan post operasi antara kedua kelompok lensa tersebut. Selain itu berdasarkan literature review oleh Montes-Mico et al didapatkan 10 dari 17 studi yang menyatakan adanya perbedaan jenis IOL yang signifikan terhadap sensitivitas kontras, 4 studi diantaranya membandingkan antara IOL asferik dan sferik dari Alcon yaitu Caporosa et al menyatakan adanya perbedaan signifikan antara IOL asferik (Tecnis, Acrysof IQ, Sofport) dengan IOL sferik (SN60AT dan AR40e) pada kondisi photopic dan mesopic. Pandita et al menyatakan adanya perbedaan signifikan antara IOL asferik Acrysof IQ (Alcon) dengan IOL sferik SN60AT (Alcon) dan SA60AT (Alcon) juga pada kondisi photopic dan mesopic. Tzelikis et al serta Mester dan Kaymak mendapatkan perbedaan yang signifikan antara IOL asferik Acrysof IQ (Alcon) dengan IOL sferik SN60AT (Alcon) pada kondisi photopic dan mesopic. Sandoval et al menyatakan adanya perbedaan signifikan antara Acrysof IQ dan SN60AT pada keadaan photopic pada 1 bulan setelah operasi namun perbedaan sensitivitas kontras tidak signifikan pada 3 bulan setelah operasi, walaupun secara keseluruhan sensitivitas kontras pada Acrysof IQ lebih tinggi dibandingkan SN60AT $(1,2,9)$. 
Perbedaan kualitas penglihatan antara mata dengan IOL asferik dan IOL sferik masih tetap menjadi perbedaan hingga saat ini, ada beberapa studi yang mendapatkan adanya perbedaan hanya pada keadaan mesopic, namun adapula yang menyatakan bahwa perbedaan tersebut dapat pula terjadi pada keadaan photopic. Pada dasarnya perbedaan tersebut terjadi karena IOL asferik dapat menurunkan aberasi sferik yang telah dibuktikan signifikan secara statistik berdasarkan pemeriksaan wavefront analysis (aberrometer) seperti pada penelitian Sandoval et al, Ohtani et al, Santhiago et al, walau kadang secara statistik ada yang tidak signifikan Kohnen et al namun dari semua data yang dikumpulkan pada penelitian Kohnen didapatkan penurunan aberasi sferik pada mata dengan IOL asferik $(1,3,6,9)$.

Faktor lainnya yang juga mempengaruhi perbedaan sensitivitas kontras adalah ukuran diameter pupil dan kondisi cahaya. Pupil yang semakin melebar maka sensitivitas kontras pada mata dengan IOL sferik akan semakin menurun bila dibandingkan mata dengan IOL asferik. Hal ini disebabkan semakin meningkatnya higherorder aberrations (HOAs) yang otomatis akan meningkatkan aberasi sferik pada pupil yang semakin lebar. Moshirfar menyatakan bahwa aberasi sferik lebih besar secara signifikan pada IOL sferik dibandingkan IOL asferik namun besarnya aberasi tersebut sangat tergantung pada ukuran pupil, dimana pada ukuran pupil 4-6 mm tetap terjadi aberasi sferik pada IOL asferik dan aberasi tersebut semakin besar pada IOL sferik. Santhiago et al menyatakan bahwa pada kelompok IOL asferik didapatkan HOAs yang lebih rendah dibandingkan kelompok IOL sferik pada pupil ukuran 5-6 mm, begitu pula sensitivitas kontras lebih baik pada kondisi mesopic. Montes-Mico et al dalam telaah literaturnya menyatakan bahwa perbedaan antara IOL asferik dan IOL sferik akan lebih konsisten ketika kondisi pencahayaan semakin berkurang dan diameter pupil yang semakin besar $(2,9,10)$.

Beberapa hal yang perlu diperhatikan diantaranya adalah ukuran pupil pada orang tua relatif lebih kecil (senile miosis). HOAs lebih dipengaruhi oleh karena aberasi asimetrikal yang tidak dapat dikompensasi oleh lensa asferik, selain itu IOL asferik yang tidak tepat akibat terjadi pergeseran atau kemiringan akan menimbulkan aberasi sferik yang lebih besar dibandingkan IOL sferik. Menurut Holladay et al pergeseran sebesar 0,4 $\mathrm{mm}$ dan kemiringan sebesar $7^{\circ}$ akan mengakibatkan IOL asferik bersifat seperti IOL sferik $(2,11)$.

Pada penelitian ini tidak dapat diketahui penyebab pasti terjadinya perbedaan sensitivitas kontras yang signifikan antara IOL asferik dan IOL sferik karena tidak dilakukan pengukuran aberasi sferik maupun diameter pupil dikarenakan keterbatasan alat. Selain itu kondisi cahaya pada penelitian ini tidak dikondisikan khusus melainkan mengikuti cahaya ruangan yang digunakan untuk pemeriksaan refraksi pasien yaitu 28 lux.

Pada penelitian ini rata-rata sensitivitas kontras pada mata post fakoemulsifikasi yang ditanam IOL asferik adalah 1,62 $(0,05)$ dan sferik adalah $1,52(0,13)$. Kedua nilai tersebut masih dalam batas normal sesuai dengan rujukan pada penellitian Holand et al yang mengambil standar sensitivitas kontras dengan Pelli-Robson cs chart abnormal adalah bila logcs $<1,50$ berdasarkan penelitian Myers et al yang mengambil data dari populasi normal sebagai kontrol. Sama seperti halnya pada penelitian
Haymes et al yang mendapatkan rentang nilai normal sensitivitas kontras Pelli-Robson pada populasi normal sebagai kontrol adalah antara 1,45-1,95 (1,79 (0,11)) $(12,13)$. Ada pendapat yang menyatakan bahwa lensa berbahan UV light filter dengan blue blocking IOLs menurunkan ketajaman visus post operasi jika dibandingkan dengan lensa yang hanya berbahan UV filter saja, dalam penelitian ini tidak didapatkan adanya perbedaan visus ataupun bcva pada kedua kelompok. Lensa tanam asferik SN60WF adalah lensa yang berbahan UV filter dengan blue blocking sedangkan IOL sferik SA60AT adalah lensa yang berbahan hanya UV filter saja. Mainster et al dan Henderson et al menyatakan bahwa penurunan visus hanya didapatkan pada kondisi scotopic (35\%), sedangkan pada kondisi photopic tidak terlalu berpengaruh (7\%). Pada penelitian ini tidak dilakukan pemeriksaan pada kondisi khusus sehingga tidak dapat dibandingkan ada atau tidaknya perbedaan ketajaman visus pada kondisi-kondisi tersebut $(14,15)$.

Beberapa faktor lain dari tindakan operasi yang dapat mempengaruhi terjadinya perubahan pada kornea dianalisa pada penelitian ini, dan berdasarkan analisa data pada hasil mengindikasikan bahwa dari segi karakteristik pt, ept, fl yang diambil untuk kelompok mata dengan IOL asferik (WF) dan kelompok mata dengan IOL sferik (AT) masih relatif homogen, selain itu bahan operasi yang digunakan seperti viskoelastik dan cara insisi juga sama pada semua pasien. Viskoelastik yang digunakan adalah bahan yang mengandung dispersive low viscosity, dan cara insisi yang dilakukan adalah clear cornea dengan panjang 2,2 $\mathrm{mm}$. Begitu pula dengan hasil analisa data demografi pasien seperti usia, jenis kelamin, mata pasien, serta hasil pemeriksaan $\mathrm{kr}$, dan bcva pasien setelah minimal satu bulan kontrol post operasi adalah homogen, dengan demikian, pengaruh lain (confounding factor) dari faktor operasi (pt, ept, fl) dan karakteristik usia, jenis kelamin, mata pasien, $\mathrm{kr}$, dan bcva 32 mata dari 23 pasien yang diamati pada kedua kelompok dapat diminimalkan agar tidak mempengaruhi variabel yang diamati.

Pemeriksaan sensitivitas kontras pada penelitian ini diambil minimal satu bulan post operasi karena diharapkan pemeriksaan sensitivitas kontras tidak lagi dipengaruhi oleh edema kornea akibat trauma post operasi. Beberapa penelitian menyatakan bahwa edema kornea berkurang mendekati sempurna seperti sebelum operasi adalah setelah satu bulan, sedangkan morfologi endotel kornea akan kembali seperti sebelum operasi setelah tiga bulan $(16,17)$.

Astigmatisme lebih dari 1,00D pada dasarnya tidak mempengaruhi sensitivitas kontras secara statistik, namun dengan adanya astigmatisme yang lebih dari 2,00D menyebabkan nilai sensitivitas kontras menurun setelah implantasi IOL pada mata. Zheng et al dalam Hashemi mendemonstrasikan penurunan sensitivitas kontras dengan adanya astigmatisme. Menurut Zheng hal ini disebabkan oleh distorsi dan kurangnya fokus yang jelas pada retina, bahkan pada mata astigmatisme myopia yang diperiksa dengan koreksi refraksi hanya mengurangi sedikit efek penurunan fokus gambar pada retina yang mengganggu sensitivitas kontras. Dalam hal ini lensa silinder menyebabkan minifikasi dan perubahan gambar pada retina yang menyebabkan menurunnya sensitivitas kontras pada mata astigmat. Oleh karena itu pada penelitian ini diambil mata dengan astigmatisme kurang dari 1,50D merujuk pada penelitian Kohnen et al yang 
mengeksklusi mata dengan astigmatisme lebih dari 1,50D $(6,18,19)$.

Kelemahan pada penelitian ini antara lain pengukuran sensitivitas kontras hanya dilakukan pada kondisi pencahayaan 28 lux, sedangkan mata pada umumnya lebih mudah membedakan kontras dalam kondisi terang (photopic, 85-160 cd/m2 atau 85-160 lux) dibandingkan pada kondisi yang kurang terang (mesopic, 3-6 cd/m2 atau 3-6 lux) atau gelap (scotopic 1-1,5 lux). Selain itu pada penelitian ini juga tidak dilakukan pengukuran pupil karena keterbatasan alat sehingga pengaruh diameter pupil tidak dievaluasi. Pada malam hari kemampuan mata untuk melihat kontras lebih diperlukan dibandingkan pada siang hari, terutama bagi mereka yang sering melakukan aktivitas atau bekerja pada malam hari misalnya menyetir, dan pada pekerjaan tertentu seperti pilot dan teknisi mesin. Pada beberapa negara maju pemeriksaan sensitivitas kontras telah dijadikan standar untuk pemeriksaan mata selain ketajaman visus untuk mendapatkan surat ijin mengemudi dan pekerjaan

\section{DAFTAR PUSTAKA}

1. Sandoval HP, Fernández de Castro LE, Vroman DT, and Solomon KD. Comparison of Visual Outcomes, Photopic Contrast Sensitivity, Wavefront Analysis, and Patient Satisfaction Following Cataract Extraction and IOL Implantation: Aspheric Vs Spherical Acrylic Lenses. Eye. 2008; 22(12): 1469-1475.

2. Montes-Mico R, Ferrer-Blasco T, and Cervino A. Analysis af the Possible Benefits of Aspheric Intraocular Lenses: Review of the Literature. Journal Cataract Refractive Surgery. 2009; 35: 172-181.

3. Ohtani S, Miyata K, Samejima T, Honbou M, and Oshika T. Intraindividual Comparison of Aspherical and Spherical Intraocular Lenses of Same Material and Platform. Ophthalmology. 2009; 116(5): 896-901.

4. Devgan U. Aspheric IOLs Improve Image Quality for Patients. New Jersey: Ocular Surgery News; 2006.

5. Wang M, Swartz T, Pepose JS, and Qazi MA. PeerReviewed Literature: Update on Aspheric IOL Technology. Cataract and Refractive Surgery Today. 2006: 20-25.

6. Kohnen T, Klaproth OK, and Bühren J. Effect of Intraocular Lens Asphericity on Quality of Vision after Cataract Removal an Intraindividual Comparison. Ophthalmology. 2009; 116(9): 1697-1706.

7. Trueb PR, Albach C, Montés-Micó R, and Ferrer-Blasco T. Visual Acuity and Contrast Sensitivity in Eyes Implanted with Aspheric and Spherical Intraocular Lenses. Ophthalmology. 2009; 116(5): 890-895.

8. Barbero S, Marcos S, Montejo J, and Dorronsoro C. Design of Isoplanatic Aspheric Monofocal Intraocular Lenses. Optics Express. 2011; 19(7): 6215-6230.

9. Santhiago MR, Netto MV, Barreto J Jr, et al. Wavefront Analysis, Contrast Sensitivity, and Depth of Focus after Cataract Surgery with Aspherical Intraocular Lens Implantation. American Journal of Ophthalmology. 2010; 149(3): 383-389.

10. Moshirfar M. Spherical Aberration of Intraocular Lenses. Journal of Ophthalmic and Vision Research. 2010; 5(4): 215-216. tertentu (pilot). Selain itu waktu pemeriksaan sensitivitas kontras yang dilakukan tidak dapat dikontrol pada penelitian ini, dengan rata-rata waktu antara satu bulan hingga tiga bulan sepuluh hari, sehingga tidak dapat dilihat perbedaan sensitivitas kontras antara satu bulan dengan tiga bulan post operasi.

Dari penelitian ini dapat diambil kesimpulan bahwa terdapat perbedaan sensitivitas kontras secara signifikan antara mata yang diberi IOL asferik dengan mata yang diberi IOL sferik. Sensitivitas kontras pada mata dengan IOL asferik lebih tinggi dibandingkan dengan sensitivitas kontras pada mata dengan IOL sferik, walau demikian nilai sensitivitas kontras mata dengan IOL asferik dan IOL sferik masih berada dalam rentang nilai normal yaitu 1,62 untuk IOL asferik dan 1,52 untuk IOL sferik. Perbedaan nilai sensitivitas kontras tersebut dapat menjadi pertimbangan dalam pemilihan IOL yang akan ditanam pada pasien katarak, terutama untuk pasien yang dalam pekerjaannya memang sangat memerlukan bukan hanya tajam penglihatan yang baik namun juga kualitas penglihatan yang baik.

11. Holladay JT, Piers PA, Koranyi G, van der Mooren M, and Norrby NE. A New Intraocular Lens Design to Reduce Spherical Aberration of Pseudophakic Eyes. Journal of Refractive Surgery. 2002; 18(6): 683-692.

12. Haymes SA, Roberts KF, Cruess AF, et al. The Letter Contrast Sensitivity Test: Clinical Evaluation of a New Design. Investigative Ophthalmology \& Visual Science. 2006; 47(6): 2739-2745.

13. Holland GN, Kappel PJ, Natta MLV, et al. Association between Abnormal Contrast Sensitivity and Mortality among People with Acquired Immunodeficiency Syndrome. American Journal of Ophthalmology. 2010; 149(5): 807-816.

14. Henderson BA and Grimes KJ. Blue-Blocking IOLs: A Complete Review of the Literature. Survey of Ophthalmology. 2010; 55(3): 284-289.

15. Mainster MA and Turner PL. Blue-blocking IOLs Decrease Photoreception without Providing Significant Photoprotection. Survey of Ophthalmology. 2010; 55(3): 272-289.

16. Suzuki H, Takahashi H, Hori J, Hiraoka M, Igarashi T, and Shiwa T. Phacoemulsification Associated Corneal Damage Evaluated by Corneal Volume. American Journal of Ophthalmology. 2006; 142(3): 525-528.

17. Lundberg $\mathrm{B}$, Jonsson $\mathrm{M}$, and Behndig $\mathrm{A}$. Postoperative Corneal Swelling Correlates Strongly to Corneal Endothelial Cell Loss After Phacoemulsification Cataract Surgery. American Journal of Ophthalmology. 2005; 139(6): 1035-1041.

18. Schmitz S, Dick HB, Krummenauer F, Schwenn O, and Krist R. Contrast Sensitivity and Glare Disability by Halogen Light after Monofocal and Multifocal Lens Implantation. British Journal of Ophthalmology. 2000; 84(10): 1109-1112.

19. Hashemi H, Khabazkhoob M, Jafarzadehpur E, Emamian $\mathrm{MH}$, Shariati $\mathrm{M}$, and Fotouhi A. Contrast SensitivityEvaluation in a Population-Based Study in Shahroud, Iran. Ophthalmology. 2012; 119(3): 541546 